\title{
Repeated acquisitions and extinctions in classical conditioning of the rabbit nictitating membrane response
}

\author{
E. James Kehoe \\ School of Psychology, The University of New South Wales, Sydney, NSW 2052, Australia
}

\begin{abstract}
The rabbit nictitating membrane (NM) response underwent successive stages of acquisition and extinction training in both delay (Experiment 1) and trace (Experiment 2) classical conditioning. In both cases, successive acquisitions became progressively faster, although the largest, most reliable acceleration occurred between the first and second acquisition. Successive extinctions were similar in rate. The results challenge contextual control theories of extinction but are consistent with attentional and layered-network models. The results are discussed with respect to their implications for the interaction between cerebellar and forebrain pathways for eyeblink conditioning.
\end{abstract}

The present experiments were aimed at resolving three questions concerning the effect of repeated cycles of acquisition and extinction training in the rabbit nictitating (NM) preparation.

First, it is uncertain whether successive acquisitions and extinctions become faster or slower. Previous studies using the rabbit NM preparation have not yielded conclusive findings (Smith and Gormezano 1965; Hoehler et al. 1973; Scavio and Thompson 1979). In the two older studies, single sessions of acquisition training were alternated with single sessions of extinction training. After the first cycle of acquisition and extinction sessions, reacquisition was virtually instantaneous and showed no changes over successive cycles. The rate of extinction, on the other hand, appeared to accelerate over successive cycles. Similarly, Scavio and Thompson (1979) observed uniformly rapid reacquisition and accelerated extinction when they used three or more sessions of extinction in each cycle. In all three studies, however, the extinction sessions did not entirely abolish responding, and they would not have abolished spontaneous recovery, which is pronounced in the rabbit NM preparation (Haberlandt et al. 1978; Napier et al. 1992). Thus, changes in the rate of reacquisition may have been obscured by spontaneous recovery from incomplete extinction. More recently, Kehoe and his associates have examined reacquisition using multiple extinction sessions to eliminate all responding, including spontaneous recovery (Napier et al. 1992; Macrae and Kehoe 1999; Weidemann and Kehoe 2003). They have consistently found that reacquisition is rapid, although not instantaneous. However, the effect of further stages of reacquisition and extinction using enough sessions to abolish the conditioned response (CR) remains to be explored.

Second, it is unknown whether delay and trace conditioning will yield comparable results. All studies described above used delay conditioning procedures, in which the conditioned stimulus (CS) filled the entire interval between its onset and the onset of the unconditioned stimulus (US), either overlapping the US (Smith and Gormezano 1965; Hoehler et al. 1973) or terminating at the time of US onset (Scavio and Thompson 1979; Napier et al. 1992). In contrast, in trace conditioning, there is a gap between the offset of the CS and the onset of the US. Although the delay and trace paradigms differ only quantitatively, trace condition-

E-mail j.kehoe@unsw.edu.au; fax +61-2-9385 3641.

Article published online before print. Article and publication date are at http:// www.learnmem.org/cgi/doi/10.1101/lm.169306. ing appears to engage pathways in the hippocampus and frontal cortex (Solomon et al. 1986; Moyer et al. 1990; Weible et al. 2000; Weiss et al. 2000), beyond the cerebellar and brainstem circuits essential for NM conditioning (Christian and Thompson 2003).

Third, the theoretical mechanisms that underpin both extinction and rapid reacquisition are still poorly understood. Pavlov's (1927) own investigations showed that extinction does not erase the original excitatory learning. Since then, the number of candidates for down-regulating responding while preserving the original learning has continued to grow (Robbins 1990; Kehoe and White 2002; Bouton 2004; Mauk and Ohyama 2004). The major theories and their respective abilities to explain the present findings will be described in the Discussion.

\section{Results}

\section{Experiment 1}

Experiment 1 contained two parts, both of which were aimed at delineating the pattern of successive acquisitions and extinctions in delay conditioning of the rabbit NM response. Part 1 used conventional, CS-alone extinction, in which the US was entirely removed during extinction training. Part 2 compared CS-alone extinction to an unpaired extinction procedure, in which the US was retained during extinction training but was well separated from the CS. In the unpaired procedure, any motivational states or contextual cues arising from US presentations would presumably be similar, if not identical, to acquisition training (Napier et al. 1992).

In both parts, the rabbits received acquisition training in which the CS-US interval (onset-onset) and CS duration was 250 msec. ${ }^{1}$ On each day of acquisition training, all rabbits received 60 CS-US trials separated by a mean intertrial interval (ITI) of $60 \mathrm{sec}$ (range $=50-70 \mathrm{sec}$ ). On each day of extinction training, a group of rabbits in both Part $1(n=6)$ and Part $2(n=7)$ received 60 CS-alone trials at the same ITI as in acquisition training. Part 2 also contained a second group $(n=7)$ that received an unpaired procedure instead of the conventional extinction procedure. The CS-alone trials were distributed in the same fashion as in the

\footnotetext{
${ }^{1}$ This procedure, in which CS offset occurs at the time of US onset, is sometimes called a "zero-trace." This procedure was used for two reasons: (1) it holds constant the duration of the CS exposed alone across acquisition and extinction sessions, and (2) it is consistent with the procedure used in previous extinction studies in the UNSW laboratory (e.g., Napier et al. 1992).
} 
conventional extinction procedure, but there was also a US-alone presentation delivered at a point halfway between the successive CS-alone trials.

Statistical analyses were conducted using planned contrasts for repeated measure designs (O'Brien and Kaiser 1985; Harris 1994). The Type I error rate was set to 0.05. In addition, for each statistical comparison, a measure of effect size is reported, specifically, the partial $\eta$ squared $\left(\eta^{2}\right)$. This measure equals SSeffect/ (SSeffect+SSerror) and represents the proportion of overall variance explained by the differences among the means. In relation to Cohen's (1988) d' measure of effect size, an $\eta^{2}$ of 0.20 corresponds to a d' $=1.00$, which would be considered a "large" effect size. For the results of the present experiments, all differences that attained statistical significance had an $\eta_{p}^{2}$ of 0.20 or greater. Finally, in the text, means are accompanied by a figure in parentheses that represents the standard error of the mean $( \pm$ SEM).

Figure 1 shows the mean percentage of CRs in Part 1 (upper
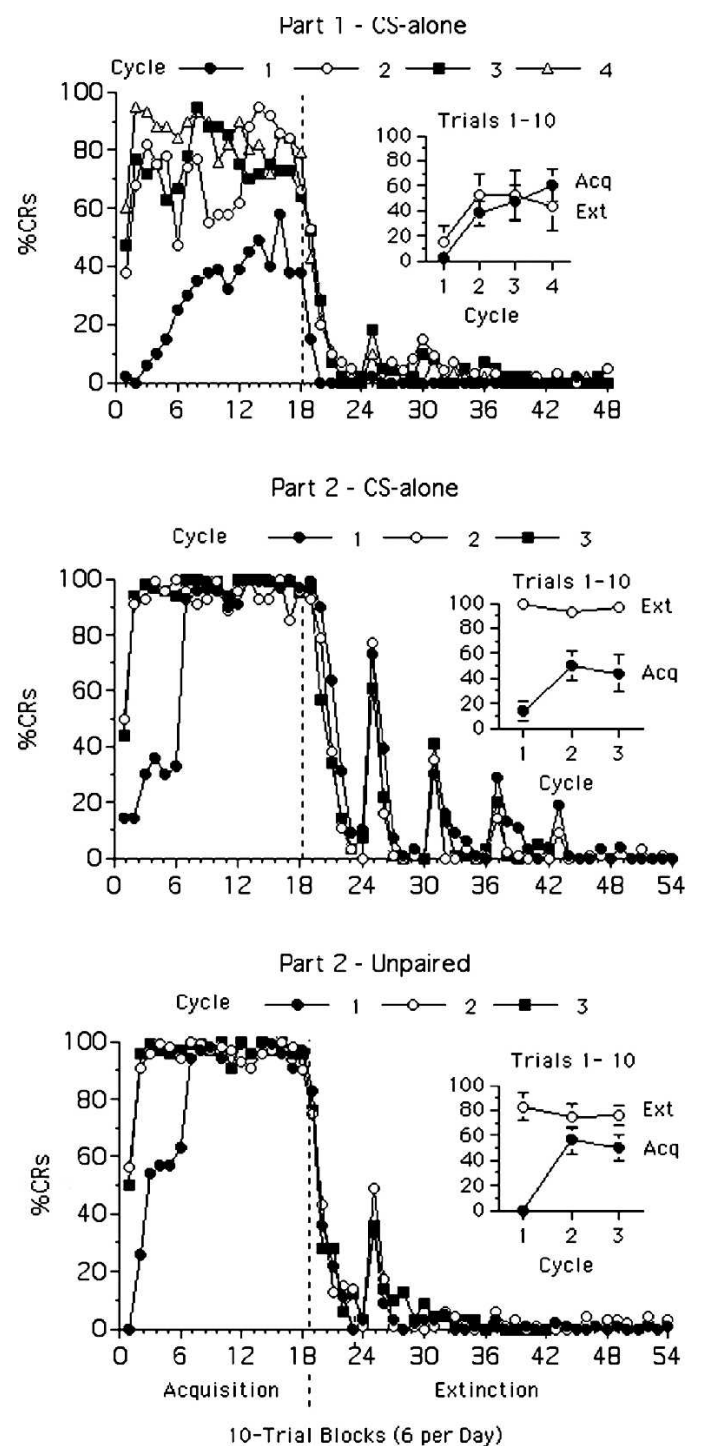

Figure 1. The upper panel shows, for Part 1 of Experiment 1, the mean percentage CRs as a function of 10-trial blocks in acquisition and extinction training. There is a separate curve for each cycle. The inset shows the mean percentage CRs in Trials 1-10 of trials in acquisition and extinction plotted as a function of cycle. The two lower panels show the corresponding plots for the CS-alone and unpaired groups in Part 2. panel) and Part 2 (lower panels) plotted as a function of 10-trial blocks in each cycle of acquisition and extinction training. The plots for each cycle are superimposed.

\section{Successive acquisitions}

Inspection of the acquisition curves shown for Part 1 reveals that initial acquisition (Cycle 1) was slow. The level of responding was still rising when the training was switched to extinction. Subsequent acquisitions, however, were faster. Responding generally reached asymptotic levels around $75 \%$ CRs by the second block of CS-US pairings, albeit with considerable variability from one block to the next.

The very slow initial acquisition and variability throughout Part 1 was atypical. However, no fault in the apparatus or procedure could be identified. The animals were healthy throughout training. The variability in the mean level of responding may have resulted from a combination of random sampling error and a small sample size.

As can be seen in the lower portion of Figure 1, overall response levels in Part 2 were higher and less variable than in Part 1. Nevertheless, in Part 2, initial acquisition was slower than the subsequent acquisitions. Specifically, responding during initial acquisition training reached levels above $90 \%$ CRs in the seventh block, but responding during subsequent acquisition cycles reached stable levels above $90 \%$ CRs by the second block.

In both parts, the increase in the rate of acquisition largely entailed the large jump between initial acquisition in Cycle 1 and reacquisition in Cycle 2. The inset panels of Figure 1 plot the mean percentage CRs in Trials 1-10 of acquisition and extinction for each cycle. As can be seen, the level of responding in acquisition training showed an abrupt rise from Cycle 1 to Cycle 2 . Across the subsequent cycles, responding appeared to slightly increase in Part 1 but slightly decrease in Part 2. Statistical analysis revealed significant linear trends across all cycles in both Part 1, $F_{(1,5)}=10.13, P<0.05, \eta_{p}^{2}=0.67$, and Part $2, F_{(1,12)}=12.16$, $P<0.01, \eta_{\mathrm{p}}^{2}=0.50$. However, when data from Cycle 1 were excluded, the small changes across successive reacquisitions did not even approach statistical significance in either part $(P>0.10)$.

\section{Successive extinctions}

With the exception of the first extinction in Part 1, the rate of extinction appeared relatively constant across successive cycles in both parts. With regard to the first extinction in Part 1, responding disappeared quickly. However, the animals in Part 1 entered extinction at a much lower level of responding than in subsequent cycles, thus making it difficult to compare the first extinction with subsequent extinctions. In contrast, in Part 2, the animals had reached similar, high asymptotes at the end of acquisition training in all cycles, thus avoiding any confounding of performance in extinction by differences in acquisition level. For both Parts 1 and 2, statistical analyses failed to reveal any significant differences in extinction across successive cycles for either Trials $1-10$ or the entire first session of extinction in each cycle (all $P>0.10$ ).

Although successive extinctions were similar, further analyses of the data from Part 2 revealed that CS-alone extinction consistently yielded a significantly higher level of responding than the unpaired procedure across all cycles. Specifically, for Trials 1-10 of extinction in all cycles, the rabbits given the CSalone procedure showed $96 \%$ CRs $( \pm 4 \%)$, while the rabbits given the unpaired procedure showed $78 \%$ CRs $( \pm 11 \%), F_{(1,12)}=10.69$, $P<0.01, \eta_{\mathrm{p}}^{2}=0.47$. Likewise, when the entire first session of extinction in each cycle was analyzed, CS-alone extinction yielded $41 \%$ CRs $( \pm 16 \%)$, and the unpaired procedure yielded $26 \%$ CRs $( \pm 14 \%), F_{(1,12)}=11.44, P<0.01, \eta_{p}^{2}=0.49$. This difference between the extinction procedures was consistent across all 
cycles of extinction and, moreover, was confined to extinction; both groups of rabbits showed similar levels of responding at each stage of acquisition training (all $P>0.10$ ).

During extinction, the entire time course of the NM movement following CS onset could be recorded without intrusion from the UR. The maximum NM movement on each of the $60 \mathrm{CS}$ presentations on the first day of extinction in each cycle for both Parts 1 and Parts 2 was examined. The mean magnitudes for each group closely paralleled their respective patterns for the percentage CR measure shown in Figure 1. This parallel agrees with previous observations that the response magnitude and CR percentage measures are well correlated in acquisition training and generalization testing (Garcia et al. 2003). However, on an individual animal basis, the reduction in response magnitude in the present study differed from the growth seen in response magnitude in acquisition seen by Garcia et al. (2003). In the present experiment, individual animals tended to show progressive declines in the NM movements from a size greater than the criterion for a CR through intermediate sizes around the criterion to a negligible size. In contrast, in acquisition training, response magnitude as measured on CS-alone trials showed an all-or-none pattern, without intermediate sizes.

The present results confirmed previous findings that, in the rabbit NM preparation, reacquisition after initial acquisition training and thorough extinction is very rapid (Napier et al. 1992; Macrae and Kehoe 1999; Weidemann and Kehoe 2003). However, subsequent reacquisitions appeared to be equally rapid. Likewise, successive extinctions all appeared to be similar, provided that asymptotic responding had been achieved in acquisition training.

The higher level of responding in extinction in the CS-alone procedure relative to the unpaired procedure was an unexpected finding. Opposite to the present results, Frey and Butler (1977) found that a CS-alone procedure produced a lower level of rabbit eyeblink responding than an unpaired procedure. More generally, however, examinations of NM responding have failed to yield any consistent or significant difference between the CSalone and unpaired extinction procedures (Napier et al. 1992; Schreurs et al. 2000; Weidemann and Kehoe 2004). In summary, a consideration of the present results together with the previous results suggests that the overall net effect of CS-alone versus unpaired procedures on extinction is probably zero.

\section{Materials and Methods}

\section{Experiment 1}

\section{Subjects}

The subjects were naive, female, albino rabbits (Oryctolagus $\mathrm{cu}$ niculus), 10-12 weeks old on arrival from the supplier. All were housed in individual cages and had unlimited access to food and water. There were 6 rabbits in Part 1 and 14 rabbits in Part 2.

\section{Apparatus}

The apparatus and the recording procedure for the NM response were patterned after those described by Gormezano (1966). The rabbits were trained individually in one of eight soundattenuating chambers. On the wall of each chamber in front of the subject was a stimulus panel. Mounted on the stimulus panel $4 \mathrm{~cm}$ above the speaker was an $8-\mathrm{W}$ neon light that served as a house light. A speaker was also mounted on the panel, $8 \mathrm{~cm}$ anterior to and $16 \mathrm{~cm}$ above the rabbit's head. The speaker provided an auditory CS. In Part 1 , the CS was a 1000-Hz, 88-dB (SPL, $\mathrm{C}$ scale) tone of 250-msec duration superimposed on an ambient noise level of $81 \mathrm{~dB}$, which was produced by an exhaust fan situated behind each subject. The US was a $3-\mathrm{mA}, 50-\mathrm{msec}, 50-\mathrm{Hz}$ AC current delivered via stainless steel Autoclip wound clips positioned $10 \mathrm{~mm}$ apart and $15 \mathrm{~mm}$ posterior to the dorsal canthus of the rabbit's right eye. In Part 2, the CS was a 77-dB (SPL, C scale), 250-msec white noise superimposed on an ambient noise level of $75 \mathrm{~dB}$ from new exhaust fans. For delivery of the US, one clip was positioned $10 \mathrm{~mm}$ posterior to the dorsal canthus of the rabbit's right eye, and the other was positioned $10 \mathrm{~mm}$ below the center of the right eye. In both parts, the interstimulus interval between CS onset and US onset was 250 msec. In Part 1, the sequence and timing of stimulus events and the response recording were controlled by an Apple II computer equipped with interfaces and software developed by Scandrett and Gormezano (1980). In Part 2, the Apple II computer was replaced by a PC programmed using LabVIEW (Version 7, National Instruments).

During training, each rabbit was restrained in a Perspex box $(425 \times 115 \times 165 \mathrm{~mm}$, internal dimensions) and held in place by inserting its head through an adjustable stock and securing its ears to the front of the stock with a polyurethane foam-covered metal clamp. A muzzle-like headset, fitted securely about the snout, supported a photoelectric transducer for detecting movements of the NM (Gormezano and Gibbs 1988). A small hook was attached to a silk loop sutured into the NM of the rabbit's right eye. The hook was connected to one end of an L-shaped crank that operated the photoelectric transducer. The signal from the transducer was amplified and transmitted to an analog-to-digital converter mounted in the computer (10-msec sample rate).

\section{Procedure}

All rabbits received one day of preparation and one day of adaptation before training began. On the preparation day, hair surrounding each rabbit's right eye was clipped and, after a local anesthetic (proxymetacaine hydrochloride) was administered, a small loop of surgical silk (000 Dynex) was sutured into, but not through, the NM of the right eye. The rabbits were then returned to their home cages. On the adaptation day, the rabbits were placed in the conditioning apparatus for $60 \mathrm{~min}$, but neither the CSs nor the US were presented.

On the day following adaptation, all rabbits in both parts received three days of CS-US training. Each day contained 60 trials, separated by a mean ITI of $60 \mathrm{sec}$ (range 50-70 sec). Following initial CS-US training, all rabbits received extinction training. In Part 1 , the rabbits $(n=6)$ received CS-alone extinction training, as did a random half of the rabbits $(n=7)$ in Part 2. The other half of the rabbits $(n=7)$ in Part 2 received explicitly unpaired training, in which CS-alone and US-alone presentations were alternated with a minimum of 20 sec between presentations. Extinction training lasted for five days in Part 1 and six days in Part 2. Subsequently, the rabbits in Part 1 received three further cycles of acquisition and extinction training identical to the first cycle. The rabbits in Part 2 received two more cycles after their first cycle.

\section{Response definition}

A CR was defined as any extension of the NM exceeding $0.5 \mathrm{~mm}$ that occurred during a 250-msec period following the onset of a CS.

\section{Results}

\section{Experiment 2}

Experiment 2 examined successive acquisitions and extinctions in three different trace conditioning groups. In all three groups $(n=8)$, the interstimulus interval between the onset of the CS and the onset of the US was $500 \mathrm{msec}$. The groups differed in the length of the trace interval between CS offset and US onset. These intervals were $50 \mathrm{msec}, 250 \mathrm{msec}$, and $450 \mathrm{msec}$. Thus, the CS durations were 450,250 , and $50 \mathrm{msec}$, respectively.

This selection of parameters was guided by two considerations. First, the trace intervals typified the values commonly used in neurobehavioral studies using the rabbit NM preparation (e.g., Solomon et al. 1986; Moyer et al. 1990; Griffin et al. 2004; Harvey et al. 2004). Second, in NM conditioning, event transitions, more so than their durations, are key influences (Kehoe 
and Napier 1991). Specifically, stimulus offset as well as stimulus onset can act as a CS in trace conditioning (Liu and Moore 1969; Gormezano 1972). When the trace CS is long enough so that the stimulus onset and stimulus offset have substantially different CS-US intervals, then the length of the trace interval between CS offset and US onset determines the rate of CR acquisition (Kehoe 1979; 1983; Kehoe and Weidemann 1999). When the duration of a trace CS has been manipulated in testing, the onset and offset of the CS each command a CR (Desmond and Moore 1991; Kehoe and Macrae 2002).

In the present experiment, the CS-US interval for CS onset was selected to be a value that by itself yields a moderate rate of $\mathrm{CR}$ acquisition while leaving enough room to manipulate the trace interval across values that produce different rates of $\mathrm{CR}$ acquisition (Smith 1968; Kehoe and Schreurs 1986; Kehoe and Macrae 2002). Specifically, the 50-msec trace interval was a minimal, nonzero value that by itself would produce little or no CR acquisition. Thus, this condition was intended to approach the delay paradigm, while still being operationally a trace paradigm. The 250-msec value is the accepted optimal interval for CR acquisition in the NM preparation and approximates the 300-msec value at which the persistence of responding during extinction has been increased by hippocampectomy (Moyer et al. 1990). Finally, the 450 -msec trace interval approximates the 500-msec value at which CR acquisition has been disrupted in hippocampectomized rabbits (e.g., Moyer et al. 1990).

The upper panels in Figure 2 show the mean percentage of CRs plotted as a function of 10-trial trial blocks in each cycle of acquisition and extinction training in each group. The plots for each cycle are superimposed. The two lower panels in Figure 2 show the mean percentage CRs in Trials 1-10 of acquisition and extinction trials in each cycle. Within each of these panels, there is a separate curve for each of the three groups.

\section{Successive acquisitions}

Examination of the acquisition curves reveals that, as seen in Experiment 1, there was a pronounced increase in the speed of acquisition between initial acquisition training and subsequent reacquisitions. Furthermore, there was a progressive increase in the rate of successive reacquisitions as measured on the first trial block of each cycle. This trend can be seen in the bottom left panel in Figure 2. This trend was confirmed statistically by a significant upward linear trend across all cycles, $F_{(1,21)}=411.36$, $P<0.01, \eta_{p}^{2}=0.95$. Furthermore, the upward linear trend remained significant even when only the reacquisitions in Cycles $2-5$ were tested, $F_{(1,21)}=30.41, P<0.01, \eta^{2}{ }_{p}=0.59$. Over all three groups, the mean level of responding rose from $48 \%$ to $75 \%$ CRs (SEMs $=5 \%)$ across Cycles 2-5. In addition, some differences appeared among the groups. Groups T50 and T450 each showed increases across Cycles 2-5, but the responding in Group T250 responding hovered around $60 \%$ CRs (SEMs $=5 \%$ ). Linear trend tests across Cycles 2-5 confirmed that the rises were significant in Group T50, $F_{(1,21)}=21.04, P<0.01, \eta^{2}=0.50$, and Group T450, $F_{(1,21)}=19.75, P<0.01, \eta^{2}=0.48$, but not in Group T250, $F<1$.

Although not obvious in Trials $1-10$, the three groups differed during their initial acquisition in Cycle 1. Specifically, Group T250 showed faster acquisition than the other two groups. On the very first day of acquisition training, Group T250 showed a mean level of $21 \%$ CRs (SEM $=8 \%$ ), while Groups T50 and T450 showed less than 5\% CRs (SEMs $<4 \%$ ). This difference persisted into the second day, in which Groups T50, T250, and T450 showed, respectively, 34\%, 70\%, and 32\% CRs (SEMs < 14\%). Thereafter, this difference gradually disappeared. By the fifth day of training, the three groups converged to levels around $75 \%$ CRs. This pattern of responding was confirmed statistically by a significant interaction of Groups (quadratic trend) $\times$ Days (lin-
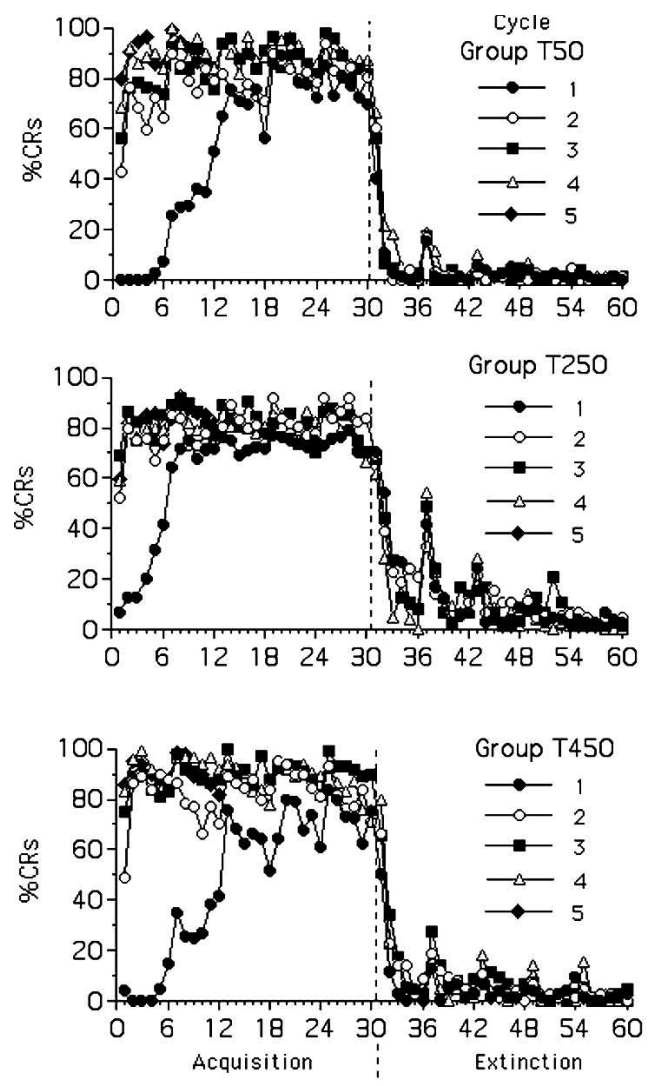

10-Trial Blocks (6 per Day)

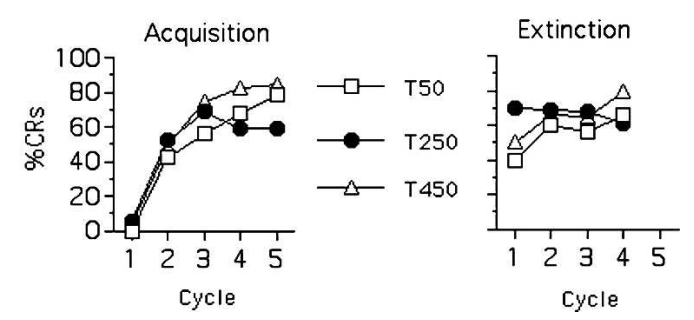

Figure 2. The three upper panels show, for Experiment 2, the mean percentage CRs as a function of 10-trial blocks in acquisition and extinction training. There is a separate panel for each group, and within each panel, a separate curve for each cycle. The two bottom panels show the mean percentage CRs in Trials 1-10 plotted as a function of cycle for each stage of acquisition (bottom left) and each stage of extinction (bottom right). There is a separate curve for each of the three trace conditioning groups.

ear trend), $F_{(1,21)}=7.83, P<0.01, \eta^{2}=0.27$. In subsequent cycles, this superiority of Group T250 disappeared (all $P>0.10$ ).

\section{Successive extinctions}

Across cycles of extinction training, the apparent differences were smaller than in acquisition. However, between the first extinction and subsequent extinctions, the rate of extinction became slower rather than faster. That is, responding during extinction training became more persistent. Averaging across groups, the mean level of responding on the first 10 trials of extinction in Cycles 1-4 were 53\%, 65\%, 63\%, and 69\% CRs $($ SEMs $=6 \%)$, respectively. Statistically, there was a significant upward linear trend across Cycles $1-4, F_{(1,21)}=7.37, P<0.01$, $\eta_{p}^{2}=0.26$, but only when Cycle 1 was included. When only Cycles 2-4 were tested, no differences were discernible, $F<1$. 
The increase in the persistence of responding during extinction between Cycle 1 and the later cycles appeared to be a flowon from a similar rise in responding at the end of the successive acquisitions. Specifically, the mean levels of responding on the last day of acquisition training for Cycles 1-4 were 75\%, 83\%, $87 \%$, and $84 \%$ CRs, respectively (SEMs $\leq 6 \%$ ). This trend was significant across Cycles 1-4, $F_{(1,21)}=9.58, P<0.01, \eta^{2}=0.31$, but not when only Cycles $2-4$ were tested, $F<1$.

Differences among the groups in extinction were modest. For Trials $1-10$ of extinction training, Group T250 showed a relatively a constant level of responding around 67\% CRs $( \pm 7 \%)$ across all cycles, while Groups T50 and T450 both showed significant increases, but only when Cycle 1 was included $(P<0.05$, smallest $\eta_{p}^{2}=0.20$ ). When the entire first day of extinction training in each cycle was analyzed, Group T250 did show significantly greater responding than the other two groups, $F_{(1,21)}=8.54, P<0.01, \eta^{2}=0.29$. In this case, the difference did not appear to be a flow-on from differences at the end of acquisition training. Specifically, for the last session of acquisition training in each cycle, any apparent differences among the groups failed to reach statistical significance, largest $F_{(1,21)}=2.52$, $P>0.10, \eta_{p}^{2}=0.11$.

An examination of the response magnitudes in extinction revealed that, as seen in Experiment 1, the group means paralleled the mean percentage CRs. As also seen in Experiment 1, the individual magnitudes showed progressive declines rather than an all-or-none pattern.

The results of Experiment 2 were consistent with those of Experiment 1 . The speed of CR acquisition showed a considerable acceleration between the initial acquisition and subsequent reacquisitions. Subsequent reacquisitions tended to show further small increases. These small increases reflected a ceiling effector perhaps better word for it is a "wall" effect-in the rate of acquisition. Consider Trials 1-10 in each cycle of acquisition. In principle, the first CS-US trial should not contain a CR at either the start of initial acquisition or after thorough extinction. Hence, a maximum of 9 trials should contain CRs. In initial acquisition, there was less than 1 CR in Trials 1-10, but, in the subsequent four reacquisitions, there were an average of $5,7,7$, and 8 CRs, respectively. Thus, the rate of reacquisition progressively approached its measurable maximum.

At least for these trace conditioning arrangements, the rate of reacquisition appeared to be similar to those seen in delay conditioning. Specifically, across all three trace conditioning groups in Experiment 2, the mean level of responding on Trials 1-10 of the first reacquisition training was $48 \%$ CRs. This level appears to fall in the middle of the range of levels seen in previous experiments using delay conditioning. Specifically, in the two delay conditioning groups in Experiment 1, the mean percentage CRs in Trials 1-10 were $37 \%$ and $53 \%$ CRs respectively. Similarly, Napier et al. (1992, Experiment 1), and Macrae and Kehoe (1999, Experiment 1) reported, respectively, levels of $24 \%$ and $60 \%$ CRs in Trials 1-10 of reacquisition training.

During extinction training, responding became slightly more persistent across successive cycles. However, this increase appeared to be a flow-on from similar increases in asymptotic performance. To test this apparent relationship, correlation coefficients were computed for performance at the end of each phase of acquisition training and the start of extinction training. For each transition, the correlations were all moderate to large, smallest $r=0.61, n=24, P<0.01$. In any event, measurement of performance in extinction was not hampered by limitations in the measurement scale. If extinction were immediate, then one CR should appear on the first CS-alone trial but not thereafter. In fact, in Trials 1-10 of the four cycles of extinction training, there were on average $5,6,6$, and 7 CRs, respectively.
Differences among the groups were modest. As expected, on the basis of the interval between the CS offset and US onset, Group T250 initially showed faster initial CR acquisition than Groups T50 or T450. This difference, however, disappeared by the end of initial acquisition training and could not be detected again during reacquisition training. A more persistent difference appeared across extinction cycles, in which Group T250 tended to show greater responding than the other two groups. Notwithstanding these differences, the pattern of successive acquisitions and extinctions in Group T250 paralleled that of the other two groups.

\section{Materials and Methods}

\section{Experiment 2}

\section{Subjects}

The subjects were 24 naive, female, albino rabbits (Oryctolagus cuniculus), 10-12 weeks old on arrival from the supplier. All were housed in individual cages and had unlimited access to food and water.

\section{Apparatus and procedure}

Unless otherwise specified, the apparatus and procedure were identical to those used in Part 2 of Experiment 1 . The CS was a $1000-\mathrm{Hz}, 82-\mathrm{dB}$ (SPL, C scale) tone superimposed on an ambient noise level of $77 \mathrm{~dB}$ produced by a combination of white noise delivered through the same speaker as the CS plus the chamber's exhaust fan. The US was a 3-mA, 50-msec, 50-Hz AC current delivered through wound clips, one positioned $10 \mathrm{~mm}$ posterior to the dorsal canthus of the rabbit's right eye and one positioned $10 \mathrm{~mm}$ below the center of the right eye. The interstimulus interval between CS onset and US onset was $500 \mathrm{msec}$.

\section{Procedure}

After preparation and adaptation, the rabbits were randomly assigned to three groups $(n=8)$, labeled as Groups T50, T250, and T450, respectively. The labels indicate that all three groups received a trace $(\mathrm{T})$ conditioning procedure in which the intervals between CS offset and US onset were $50 \mathrm{msec}, 250 \mathrm{msec}$, and 450 msec, respectively. Thus, the CS durations were, respectively, 450 msec, $250 \mathrm{msec}$, and $50 \mathrm{msec}$. All groups received four cycles of acquisition and extinction training. Each stage of acquisition entailed five days, each containing 60 CS-US trials, and each stage of extinction entailed five days, each containing 60 CS-alone trials (mean ITI $=60 \mathrm{sec}$, range $50-70 \mathrm{sec}$ ). After the fourth extinction stage, all groups received a fifth stage of acquisition training containing two days of 60 CS-US pairings.

\section{Discussion}

The results from both experiments were consistent. First, initial CR acquisition was relatively slow, but subsequent reacquisitions were faster and approached their measurable maximum. Second, the rate of successive extinctions appeared to remain relatively constant, once increases in the level of responding at the end of acquisition were taken into account.

The large jump in the rate of CR acquisition between the initial training and subsequent reacquisition training confirms previous findings that reacquisition is rapid even when extinction training has entirely eliminated CRs (Napier et al. 1992; Macrae and Kehoe 1999; Weidemann and Kehoe 2003). Exactly like the previous studies, Experiments 1 and 2 used a delay conditioning procedure and an optimal, 250-msec CS-US interval. Experiment 2, however, demonstrated the generality of rapid reacquisition by using a trace conditioning procedure, in which the CS-US interval (onset to onset) was moderately long (500 msec) and there were three different arrangements of the trace interval and CS duration.

With respect to successive extinctions, they occurred at 
about the same rate. This outcome diverges dramatically from the results of previous studies, in which extinction became progressively faster (Smith and Gormezano 1965; Hoehler et al. 1973; Scavio and Thompson 1979). In the present experiments, each phase of extinction was conducted over several sessions until extinction was complete. In contrast, the previous studies never permitted complete extinction to occur before reacquisition training was started. Thus, the progressive decline in extinction performance seen across successive cycles may have reflected the gradual completion of extinction, albeit interrupted by reacquisition sessions.

Before detailing the specific theoretical implications of the present findings, one broad implication for theory should be noted. Eyeblink conditioning has been classified as the archetypal "slow" system based on the relatively large number of CSUS pairings needed to produce CRs relative to other response systems, for example, heart rate (Lennartz and Weinberger 1992, 1994). However, CR acquisition in the rabbit NM preparation is not irretrievably slow. The number of trials required for initial CR acquisition can be reduced from more than 100 CS-US pairings under massed conditions to less than 10 when only a single CSUS pairing is presented every $24 \mathrm{~h}$ (Kehoe and Macrae 1994). The present results show that similar accelerations, albeit in the form of reacquisition training, can be achieved using massed CS-US pairings. Moreover, this acceleration does not require that initial CR acquisition be complete. In Part 1 of Experiment 1, initial CR acquisition had only reached mean levels around 50\% CRs before extinction training. Yet, reacquisition was substantially faster than initial acquisition. Similarly, Weidemann and Kehoe (2003) also saw rapid reacquisition after they conducted brief initial acquisition training consisting of 45 CS-US trials, which yielded a level of $50 \%$ CRs.

Since Pavlov's (1927) first studies, extinction has been recognized as a down-regulation of responding rather than an erasure of the initial excitatory learning. However, no single theoretical mechanism seems to be entirely responsible for both the down-regulation and subsequent up-regulation that can be obtained in a variety of ways, including the spontaneous recovery and rapid reacquisition seen in the present experiments. In fact, the list of possible contributors to extinction and recovery has grown steadily in recent years (Robbins 1990; Kehoe and White 2002; Bouton 2004). Among these possibilities, there are three main approaches, all of which can be evaluated against the present findings.

\section{Context discrimination theories}

First, a popular type of theory entails discrimination between the context of acquisition versus the context of extinction (Tyler et al. 1953; Capaldi 1994; Bouton 2004). In conventional extinction, the CS is presented alone, and the US is removed from training. Thus, the context of extinction will lack the emotional and sensory aftereffects of the US that were present in the context of acquisition. When the US is reintroduced as part of reacquisition training, the context of acquisition will be reinstated, the excitatory associations formed in acquisition will be strongly activated, and any inhibitory associations acquired during extinction will only be weakly activated. Thus, CRs should be instantaneously reinstated after presentations of the US, without further CS-US pairings. By the same token, these theories also predict that, after reacquisition, a reintroduction of extinction and its context should produce an instantaneous decline in responding as the inhibitory associations acquired in the first extinction are reactivated. Contrary to these predictions, acquisition became progressively faster in the present experiments but never became instantaneous. Likewise, extinction never became instantaneous; the rate of extinction appeared to be constant across successive cycles.

A defender of context discrimination theories could argue that several US presentations might be required to reinstate the US-related internal context (Bouton 2004). However, attempts to use multiple US presentations to reinstate extinguished CRs in the rabbit NM preparation have been unsuccessful (Napier et al. 1992; Weidemann and Kehoe 2004). Looking further afield, the electrotactile US typically used in eyeblink studies may be too brief $(<100 \mathrm{msec})$ and/or too localized to produce the internal contextual cues needed for reinstatement. Although asserting the null hypothesis is risky, there are two lines of evidence for this assertion:

1. Studies of single alternation behavior, in which CS-US trials predict CS-alone trials and vice versa, have indicated that traces of the US effectively last for only a few seconds in terms of their ability to control overt CRs in the NM preparation (Hoehler and Leonard 1973; Hoehler and Thompson 1979). Thus, reinstatement might occur if initial acquisition training was conducted with very short ITIs, say, $10 \mathrm{sec}$, rather than the more commonly used 30-60 sec intervals.

2. In studies of extinction, continued presentations of the US intermixed with CS-alone presentations do not appear to reduce the discriminability of extinction training from acquisition training. As described previously, all possible outcomes have been obtained, and the net effect of an unpaired extinction procedure in altering the rate of extinction has appeared to be zero relative to the CS-alone procedure in rabbit eyeblink conditioning (Frey and Butler 1977; Napier et al. 1992; Schreurs et al. 2000; Weidemann and Kehoe 2004).

\section{Attentional theories}

Attentional theories were, among other things, originally aimed at explaining increases in the speed of successive discrimination reversals in instrumental learning (Sutherland and Mackintosh 1971). As applied to classical conditioning, these theories would contend that the CS becomes increasingly salient during both excitatory and inhibitory learning. Thus, successive acquisitions and extinctions should become increasingly rapid, because the increase in CS salience will lead to progressively faster changes in the assignment of excitatory versus inhibitory response tendencies to a CS.

More recent versions of attentional theory assume that changes in CS salience depend on how well the CS predicts the US or its absence (Mackintosh 1975; Pearce and Hall 1980; Lubow et al. 1981; Lubow 1989). For example, Pearce and Hall (1980) propose that CS "associability" follows a biphasic time course during both acquisition and extinction training. Immediately following a switch from CS-US pairings to CS-alone presentations or vice versa, CS associability would increase, because the predictive value of the CS would differ dramatically from the changed outcome of each trial. Then, as the associative strength of the CS increasingly matches the outcome of the trials, its associability would decline.

According to these recent attentional theories, the speed of successive acquisitions and extinctions would depend on the associability of the CS at the end of each stage of training. Changes in responding would become faster if CS associability at the end of either acquisition or extinction training was greater than the value of the CS at the start of the experiment. Conversely, if the associability of the CS were reduced to near zero or, at least, a value less than its original value, then successive acquisitions and extinctions would become slower, not faster (Bouton 1986).

Both traditional and recent attentional theories can explain the present results to some degree. For these theories, the ideal 
result would have been symmetric changes in the speed of successive acquisitions and extinctions. In fact, the observed changes were asymmetric. Acquisitions tended to become progressively faster, while extinctions remained unchanged. However, this lack of symmetry can be explained by traditional attentional theory if most of the increase in CS salience occurs during initial CS-US training. Similarly, with respect to recent attentional theories, CS associability may never quite drop back to its original value at the start of initial acquisition. This increase in CS salience would then carry through to the first extinction and all later cycles.

\section{Layered associative networks}

Minimalist layered networks, like the one shown in Figure 3, have been used to explain extinction and later recovery of CRs (Kehoe 1988; Macrae and Kehoe 1999; Weidemann and Kehoe 2003, 2004, 2005). This kind of model represents a simplified framework for what, in neural reality, is almost certainly a network of parallel excitatory and inhibitory connections with multiple sites of plasticity (Cohen 1984; Medina and Mauk 2000).

In the network shown in Figure 3, changes in responding depend on two associative links wired in series, specifically, CS-X and $\mathrm{X}-\mathrm{Y} .^{2}$ During initial CS-US acquisition training, the CS-X connection is strengthened through presentations of the CS prior to activation of the $\mathrm{X}$ unit by the US. The $\mathrm{X}-\mathrm{Y}$ connection begins to increase in strength once the CS-X connection becomes strong enough to activate the $\mathrm{X}$ unit prior to the activation of the $\mathrm{Y}$ unit by the US. CRs begin to appear once the CS-X and $\mathrm{X}-\mathrm{Y}$ connections are both strong enough. At the start of extinction, both the CS-X and $\mathrm{X}-\mathrm{Y}$ connections weaken to some degree. However, as the CS-X connection weakens, the $\mathrm{X}$ unit would be activated less and less often. In turn, the Y unit would be activated less and less often by the $\mathrm{X}$ unit. Hence, much of the $\mathrm{X}-\mathrm{Y}$ excitatory association is largely preserved despite the absence of US inputs. This residual $\mathrm{X}-\mathrm{Y}$ excitatory association promotes rapid reacquisition. As the original $\mathrm{CS}-\mathrm{X}$ connection is restrengthened, it can capitalize on this residual association. As soon as the CS starts to reactivate the $\mathrm{X}$ unit, the $\mathrm{X}$ unit will activate the $\mathrm{Y}$ unit, and CRs will appear much sooner in reacquisition training than in initial acquisition.

This model can explain how, in the present experiments, successive acquisitions became progressively faster while successive extinctions remained relatively constant in speed. First, the model predicts that initial acquisition will be relatively slow, because the CS-X connection must be at least partially established before the $\mathrm{X}-\mathrm{Y}$ connection can even start to be formed. Second, if the $\mathrm{X}-\mathrm{Y}$ connection is fully saturated by the end of initial acquisition, then the subsequent extinctions and reacquisitions depend entirely on the rate at which the CS-X connection is reduced or increased, respectively. Third, even if the X-Y con-

${ }^{2}$ Each connection is strengthened according to an error correction rule (Bush and Mosteller 1951), in which changes in associative strength $(\Delta \mathrm{V})$ are proportional to the difference between the maximum level of association supportable by the US input $(\lambda)$ and the current strength of that connection's associative strength $(\mathrm{V}): \Delta \mathrm{V} \propto(\lambda-\mathrm{V})$. Removal of the US in extinction training reduces $\lambda$ to zero, making $\Delta \mathrm{V}$ negative. In the basic error correction rule, a negative value for $\Delta V$ forces a decline in associative strength $(V)$ until it reaches a zero level. However, recent variants on the error correction rule have partitioned the associative strength of each connection into excitatory and inhibitory components (Pearce 1987, 1994; Macrae and Kehoe 1999). Whenever $\Delta \mathrm{V}$ is positive $(\lambda>V)$, the excitatory component is increased, and, whenever $\Delta V$ is negative $(\lambda<V)$, the inhibitory component is increased. Moreover, declines in excitation and increases in inhibition may not be mutually exclusive; response loss may reflect the aggregate effect of both processes operating in parallel (Klopf 1988). For present purposes, all variants of the error correction rule predict that the net associative strength, whatever its composition, will decline when a CS is not followed by the US.

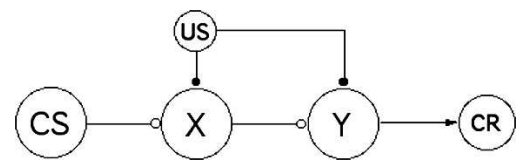

Figure 3. A layered network in which a CS has an associative linkage with an intermediate unit $(X)$, which in turn has an associative linkage with a unit $(Y)$ that ultimately projects to a motor center that generates the CR. The unconditioned stimulus (US) sends inputs to both the $X$ and $Y$ units (Kehoe and White 2002).

nection is not saturated at the end of the initial acquisition, it will still be largely protected during extinction, but in the subsequent reacquisitions, it will undergo further strengthening. Thus, as seen in the present results, the rate of subsequent acquisitions would rise, and subsequent extinctions would, if anything, tend to become slightly slower rather than faster.

\section{Conclusions}

In conclusion, the present results most strongly favor a layered network model. Having said that, attentional theories can also explain the results nearly as well. This conclusion may seem unsatisfying until one recognizes that the layered network models and attentional models have similar structures. They both assume that CR acquisition requires two types of learning: a type of CS-specific learning and a type of learning that ultimately connects the CS to the CR. Where they differ most dramatically concerns which type of learning is most profoundly affected during extinction and reacquisition. The layered network model presented here assumes that the CS-specific learning-the CS-X connection-will be most affected, while the interior X-Y connection will be largely unchanged. Conversely, traditional attentional models assume that the CS-specific learning is relatively stable after initial acquisition, while extinction and reacquisition training each rearrange excitatory and inhibitory stimulus-response assignments. The more recent associability theories take a middle road, arguing that both types of learning will be affected concurrently. Given this structural convergence among theories, the big question becomes ascertaining how much each type of learning is affected during extinction and reacquisition.

More speculatively, this question may be linked to identifying the roles played by cerebellar and hippocampal pathways in eyeblink conditioning. Cerebellar pathways are essential for the acquisition and expression of the CR in the rabbit NM preparation (Hesslow and Yeo 2002; Christian and Thompson 2003). However, the hippocampus and frontal cortex become engaged in CR acquisition when the temporal demands are increased by using larger gaps in trace conditioning (Solomon et al. 1986; Moyer et al. 1990; McEchron and Disterhoft 1999; Weible et al. 2000) or longer CS-US intervals in delay conditioning (Beylin et al. 2001). Both cerebellar and hippocampal pathways appear to contribute to conventional extinction of the CR in the rabbit NM preparation (Robleto et al. 2004). In the cerebellum, reversible inactivation of the anterior interpositus nucleus, which is essential to CR acquisition, prevents extinction of the CR (Hardiman et al. 1996; Ramnani and Yeo 1996; Robleto et al. 2004), as can lesions of the anterior lobe of cerebellar cortex (Perrett and Mauk 1995; Garcia et al. 1999). Similarly, lesions of the hippocampus have impeded extinction of well-established CRs after both delay conditioning (Schmaltz and Theios 1972; Powell and Buchanan 1980; Akase et al. 1989) and short trace (300-msec) conditioning (Moyer et al. 1990).

It would be premature to link the hippocampus and cerebellar pathways in a one-to-one fashion to the conceptual processes postulated in the behavioral theories. The theories themselves do

\section{Learning \& Memory}


not constrain the location of their neural substrates. Among the cerebellar pathways, the interconnections between the interpositus nucleus and cerebellar cortex are certainly rich enough to accommodate mechanisms like those proposed in the minimalist network shown in Figure 3. Even the internal connections among cells with the interpositus nucleus may be sufficient. In fact, because the units of a layered network are only conceptual neurons, their actual counterparts could be portions of the dendritic tree in single neurons (Leuner et al. 2003).

Moreover, the mechanisms proposed in the alternative behavioral theories are not mutually exclusive. Kehoe and White (2002) have proposed a hybrid model (Figure 4) that integrates mechanisms thought to be key contributors to extinction. At its core is a layered network like the one shown in Figure 3. In the hybrid model, however, the generic associative linkages have been replaced by parallel excitatory and inhibitory linkages to acknowledge their respective contributions (Robleto et al. 2004). For example, in short-ISI delay conditioning in the rabbit NM preparation, hippocampal lesions appear to have no impact on excitatory processes of acquisition but do impede extinction and thus perhaps damage inhibitory mechanisms (Schmaltz and Theios 1972; Berger and Orr 1983; Akase et al. 1989).

Scanning from left to right in Figure 4, the model includes potential contributions from contextual processes. Although they did not appear to play a role in the present results, the rabbit NM response is sensitive to both the global context provided by the apparatus cues (Hinson 1982; Kim 1986; Saladin and Tait 1986; Kehoe et al. 2004; Poulos et al. 2004) and conditional cues (occasion-setters) that have ranged up to a minute in length (Macrae and Kehoe 1995; Weidemann and Kehoe 1997; Rogers and Steinmetz 1998; Kehoe and Boesenberg 2002). Furthermore, the US-related internal context has the potential to make a contribution. In particular, strict alternation of CS-US and CS-alone trials produces an alternation of CR-like activity in the hippocampus even though this activity is not expressed in the NM response (Hoehler and Thompson 1979).

The possible contribution from CS salience postulated in attentional theories is depicted by a loop $(\alpha)$ from the output of the Y unit to the CS unit. This loop effectively amplifies the CS and would be important when initial CS salience is low. In particular, the neural encoding of the CS is thought to decline in intensity starting about $250 \mathrm{msec}$ after CS onset, especially in trace conditioning in which there is no continuing stimulus input to sustain CS activity (Gormezano 1972; Desmond and Moore 1988; Kehoe and Napier 1991). This loop may be mediated through the hippocampus and thus explain why conditioning becomes hippocampally dependent as the trace interval and/ or the overall CS-US interval is increased.

The model also includes a negative feedback loop $\left(\mathrm{I}_{\mathrm{R}}\right)$ from the CR unit to the output from the Y unit. Thus, as CRs are generated during a training session, further CRs would be inhibited. However, this inhibition is presumed to dissipate between sessions (Hull 1943). This loop is needed to explain the pattern of

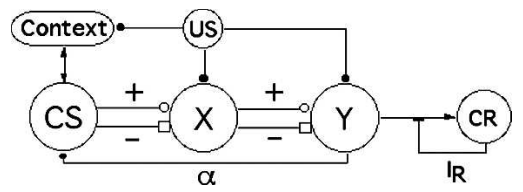

Figure 4. A layered network in which a CS has excitatory and inhibitory associative linkages with an intermediate unit $(X)$, which in turn has excitatory and inhibitory associative linkages with an output unit ( $Y$ ). The unconditioned stimulus (US) sends inputs to the $\mathrm{X}$ unit, $\mathrm{Y}$ unit, and Context inputs. There are feedback loops $(\alpha)$ from the $Y$ output to the CS input unit and $\left(I_{R}\right)$ from the motor units (CR) to the $Y$ output (Kehoe and White 2002). within-session declines and between-session spontaneous recovery seen in the early sessions of extinction, both in the present experiments and in virtually every instance of extinction in the rabbit NM preparation (e.g., Schneiderman and Gormezano 1964; Napier et al. 1992; Kehoe and White 2002).

At present, the evidence for inhibitory response feedback in the pathways for the NM response is contradictory. In favor of such a loop, Krupa and Thompson (2003) found that blocking activity in the motor nuclei for the rabbit NM response also prevented extinction of the CR. On the other hand, Robleto et al. (2004) blocked the red nucleus that drives the motor nuclei, and extinction did occur. Exactly how this contradiction will be resolved remains to be seen. However, if something like IR exists, it may be internal to the cerebellum and separate from the final motor output.

\section{Acknowledgments}

Preparation of this manuscript was supported by Australian Research Council Grants A79917018 and DP0344082. The author thanks Huong Huynh and Stephanie Dartnall for their assistance in data collection and preparation of the manuscript. These experiments were approved by the UNSW Animal Care and Ethics Committee in compliance with state and federal legislation.

\section{References}

Akase, E., Alkon, D.L., and Disterhoft, J.F. 1989. Hippocampal lesions impair memory of short delay conditioned eye blink in rabbits. Behav. Neurosci. 103: 935-943.

Berger, T.W. and Orr, W.B. 1983. Hippocampectomy selectively disrupts discrimination reversal conditioning of the rabbit nictitating membrane response. Behav. Brain Res. 8: 49-68.

Beylin, A.V., Ganghi, C.C., Wood, G.E., Talk, A.C., Matzel, L.D., and Shors, T.J. 2001. The role of the hippocampus in trace conditioning: Temporal discontinuity or task difficulty? Neurobiol. Learn. Mem. 76: $447-461$.

Bouton, M.E. 1986. Slow reacquisition following extinction of conditioned suppression. Learn. Motiv. 17: 1-15.

. 2004. Context and behavioral processes in extinction. Learn. Mem. 11: 485-494.

Bush, R.R. and Mosteller, F.A. 1951. A mathematical model for simple learning. Psychol. Rev. 58: 313-323.

Capaldi, E.J. 1994. The sequential view: From rapidly fading stimulus traces to the organization of memory and the abstract concept of number. Psychon. Bull. Rev. 1: 156-181.

Christian, K.M. and Thompson, R.F. 2003. Neural substrates of eyeblink conditioning: Acquisition and retention. Learn. Mem. 11: 427-455.

Cohen, D.H. 1984. Identification of vertebrate neurons modified during learning: Analysis of sensory pathways. In Primary neural substrates of learning and behavioral change (eds. D.L. Alkon and J. Farley), pp. 129-154. Cambridge University Press, New York.

Cohen, J. 1988. Statistical power analysis for the behavioral sciences, 2nd ed. Erlbaum, Hillsdale, NJ.

Desmond, J.E. and Moore, J.W. 1988. Adaptive timing in neural networks: The conditioned response. Biol. Cybern. 58: 405-415. . 1991. Altering the synchrony of stimulus trace processes: Tests of a neural-network model. Biol. Cybern. 65: 161-169.

Frey, P.W. and Butler, C. 1977. Extinction after aversive conditioning: An associative or nonassociative process? Learn. Motiv. 8: 1-17.

Garcia, K.S., Steele, P.M., and Mauk, M.D. 1999. Cerebellar cortex lesions prevent acquisition of conditioned eyelid responses. $J$. Neurosci. 19: 10940-10947.

Garcia, K.S., Mauk, M.D., Weidemann, G., and Kehoe, E.J. 2003. Covariation of alternative measures of responding in rabbit (Oryctolagus cuniculus) eyeblink conditioning during acquisition training and tone generalization. Behav. Neurosci. 117: 292-303.

Gormezano, I. 1966. Classical conditioning. In Experimental methods and instrumentation in psychology. (ed. J.B. Sidowski), pp. 385-420, McGraw-Hill, New York.

- 1972. Investigations of defense and reward conditioning in the rabbit. In Classical conditioning II: Current research and theory (eds. A.H. Black and W.F. Prokasy), pp. 151-181, Appleton-Century-Crofts, New York.

Gormezano, I. and Gibbs, C.M. 1988. Transduction of the rabbit's nictitating membrane response. Behav. Res. Meth. Instrum. Comput. 20: $18-21$.

Griffin, A.L., Asaka, Y., Darling, R.D., and Berry, S. 2004. 
Theta-contingent trial presentation accelerates learning rate and enhances hippocampal plasticity during trace eyeblink conditioning. Behav. Neurosci. 118: 403-411.

Haberlandt, K., Hamsher, K., and Kennedy, A.W. 1978. Spontaneous recovery in rabbit eyelid conditioning. J. Gen. Psychol. 98: 241-244.

Hardiman, M.J., Ramnani, N., and Yeo, C.H. 1996. Reversible inactivation of the cerebellum with muscimol prevents acquisition and extinction of conditioned nictitating membrane responses in the rabbit. Exp. Brain Res. 110: 235-247.

Harris, R.J. 1994. ANOVA: An analysis of variance primer. Peacock, Itasca, IL.

Harvey, J.A., Quinn, J.L., Liu, R., Aloyo, V.J., and Romano, A.G. 2004. Selective remodeling of rabbit frontal cortex: Relationship between 5-HT-sub(2A) receptor density and associative learning. Psychopharmacology 172: 435-442.

Hesslow, G. and Yeo, C.H. 2002. The functional anatomy of skeletal conditioning. In A neuroscientist's guide to classical conditioning (ed. J.W. Moore), pp. 86-146. Springer, New York.

Hinson, R.E. 1982. Effects of UCS preexposure on excitatory and inhibitory rabbit eyelid conditioning: An associative effect of conditioned contextual stimuli. J. Exp. Psychol. Anim. Behav. Proc. 8: $49-61$

Hoehler, F.K. and Leonard, D.W. 1973. Classical nictitating membrane conditioning in the rabbit (Oryctolagus cuniculus): Single alternation with differential intertrial intervals. J. Comp. Physiol. Psychol. 85: $277-288$.

Hoehler, F.K. and Thompson, R.F. 1979. The effect of temporal single alternation on learned increase in hippocampal unit activity in classical conditioning of the rabbit nictitating membrane response. Physiol. Psychol. 7: 345-351.

Hoehler, F.K., Kirschenbaum, D.S., and Leonard, D.W. 1973. The effects of overtraining and successive extinctions upon nictitating membrane conditioning in the rabbit. Learn. Motiv. 4: 91-101.

Hull, C.L. 1943. Principles of behavior. Appleton-Century-Crofts, New York.

Kehoe, E.J. 1979. The role of CS-US contiguity in classical conditioning of the rabbit's nictitating membrane response to serial stimuli. Learn. Motiv. 10: 23-38.

-1983. CS-US contiguity and CS intensity in conditioning of the rabbit's nictitating membrane response to serial compound stimuli. J. Exp. Psychol. Anim. Behav. Proc. 9: 307-319.

- 1988. A layered network model of associative learning: Learning-to-learn and configuration. Psychol. Rev. 95: 411-433.

Kehoe, E.J. and Boesenberg, K.G. 2002. Temporal discrimination using different feature-target intervals in classical conditioning of the rabbit's nictitating membrane response. Anim. Learn. Behav. 30: $208-216$.

Kehoe, E.J. and Macrae, M. 1994. Classical conditioning of the rabbit nictitating membrane response can be fast or slow: Implications for Lennartz and Weinberger's (1992) two-factor theory. Psychobiology 22: $1-4$.

2002. Fundamental behavioral methods and findings in classical conditioning. In A neuroscientist's guide to classical conditioning (ed. J.W. Moore), pp. 171-231, Springer, New York.

Kehoe, E.J. and Napier, R.M. 1991. In the blink of an eye: Real-time stimulus factors in delay and trace conditioning of the rabbit's nictitating membrane response. Q. J. Exp. Psychol. 43B: 257-277.

Kehoe, E.J. and Schreurs, B.G. 1986. Compound-component differentiation as a function of CS-US interval and CS duration in the rabbit's nictitating membrane response. Anim. Learn. Behav. 14: $144-154$

Kehoe, E.J. and Weidemann, G. 1999. Within-stimulus competition in trace conditioning of the rabbit's nictitating membrane response. Psychobiology 27: 72-84.

Kehoe, E.J. and White, N.E. 2002. Extinction revisited: Similarities between extinction and reductions in US intensity in classical conditioning of the rabbit's nictitating membrane response. Anim. Learn. Behav. 30: 96-111.

Kehoe, E.J., Weidemann, G., and Dartnall, S. 2004. Apparatus exposure produces profound declines in the rabbit's conditioned nictitating membrane response to discrete conditioned stimuli. J. Exp. Psychol. Anim. Behav. Proc. 30: 259-270.

Kim, K.-S. 1986. Effects of context manipulation on latent inhibition: A study on the nature of context in classical conditioning. Korean J. Psychol. 5: 75-86.

Klopf, A.H. 1988. A neuronal model of classical conditioning. Psychobiology 16: 85-125.

Krupa, D.J. and Thompson, R.F. 2003. Inhibiting the expression of a classically conditioned behavior prevents its extinction. J. Neurosci. 23: $10577-10584$.

Lennartz, R.C. and Weinberger, N.M. 1992. Analysis of response systems in Pavlovian conditioning reveals rapidly versus slowly acquired conditioned responses: Support for two factors, implications for behavior and neurobiology. Psychobiology 20: 93-119.

. 1994. A comparison of nonspecific and nictitating membrane conditioned responses: Additional support for two-factor theories. Psychobiology 22: 5-15.

Leuner, B., Falduto, J., and Shors, T.J. 2003. Associative memory formation increases the observation of dendritic spines in the hippocampus. J. Neurosci. 23: 659-665.

Liu, S. and Moore, J.W. 1969. Auditory differential conditioning of the rabbit nictitating membrane response: IV. Training based on stimulus offset and the effect of an intertrial tone. Psychonomic Science 15: 128-129.

Lubow, R.E. 1989. Latent inhibition and conditioned attention theory. Cambridge University Press, Cambridge, UK.

Lubow, R.E., Weiner, I., and Scnhur, P. 1981. Conditioned attention theory. In The psychology of learning and motivation (ed. G.H. Bower), Vol. 15, pp. 1-49, Academic Press, San Diego, CA.

Mackintosh, N.J. 1975. A theory of attention: Variation in the associability of stimuli with reinforcement. Psychol. Rev. 82: $276-298$.

Macrae, M. and Kehoe, E.J. 1995. Transfer between conditional and discrete discriminations in conditioning of the rabbit nictitating membrane response. Learn. Motiv. 26: 380-402.

. 1999. Savings after extinction in conditioning of the rabbit's nictitating membrane response. Psychobiology 27: 85-94.

Mauk, M.D. and Ohyama, T. 2004. Extinction as new learning versus unlearning: Considerations from a computer simulation of the cerebellum. Learn. Mem. 11: 566-571.

McEchron, M.D. and Disterhoft, J.F. 1999. Hippocampal encoding of non-spatial trace conditioning. Hippocampus 9: 385-396.

Medina, J.F. and Mauk, M.D. 2000. Computer simulation of cerebellar information processing. Nat. Neurosci. 3: 1205-1211.

Moyer, J.R., Deyo, R.A., and Disterhoft, J.F. 1990. Hippocampectomy disrupts trace eye-blink conditioning in rabbits. Behav. Neurosci. 104: $243-252$.

Napier, R.M., Macrae, M., and Kehoe, E.J. 1992. Rapid reacquisition in conditioning of the rabbit's nictitating membrane response. J. Exp. Psychol. Anim. Behav. Proc. 18: 182-192.

O'Brien, R.G. and Kaiser, M.K. 1985. MANOVA method for analyzing repeated measures designs: An extensive primer. Psychol. Bull. 97: 316-333.

Pavlov, I.P. 1927. Conditioned reflexes: An investigation of the physiological activity of the cerebral cortex. Oxford University Press, London, UK.

Pearce, J.M. 1987. A model for stimulus generalization in Pavlovian conditioning. Psychol. Rev. 94: 61-73.

. 1994. Similarity and discrimination: A selective review and a connectionist model. Psychol. Rev. 101: 587-607.

Pearce, J.M. and Hall, G. 1980. A model for Pavlovian learning: Variations in the effectiveness of conditioned but not of unconditioned stimuli. Psychol. Rev. 87: 532-552.

Perrett, S.P. and Mauk, M.D. 1995. Extinction of conditioned eyelid responses requires the anterior lobe of the cerebellar cortex. $J$. Neurosci. 15: 2074-2080.

Poulos, A.M., Pakaprot, N., Mahdi, B., Kehoe, E., and Thompson, R.F. 2004. The effects of posttraining exposure to the conditioning apparatus in delay eyeblink conditioning. Abstract Viewer/Itinerary Planner, Program No. 325.6. Society for Neuroscience, Washington, DC.

Powell, D.A. and Buchanan, S. 1980. Autonomic-somatic relationships in the rabbit (Oryctolagus cuniculus): Effects of hippocampal lesions. Physiol. Psychol. 8: 455-462.

Ramnani, N. and Yeo, C.H. 1996. Reversible inactivations of the cerebellum prevent the extinction of conditioned nictitating membrane responses in rabbits. J. Physiol. 495: 159-168.

Robbins, S.J. 1990. Mechanisms underlying spontaneous recovery in autoshaping. J. Exp. Psychol. Anim. Behav. Proc. 16: 235-249.

Robleto, K., Poulos, A.M., and Thompson, R.F. 2004. Brain mechanisms of extinction of the classical conditioned eyeblink response. Learn. Mem. 11: 517-524.

Rogers, R.F. and Steinmetz, J.E. 1998. Contextually based conditional discrimination of the rabbit eyeblink response. Neurobiol. Learn. Mem. 69: 307-319.

Saladin, M.E. and Tait, R.W. 1986. US preexposures retard excitatory and facilitate inhibitory conditioning of the rabbit's nictitating membrane response. Anim. Learn. Behav. 4: 121-132.

Scandrett, J. and Gormezano, I. 1980. Microprocessor control and A/D data acquisition in classical conditioning. Behav. Res. Meth. Instrum. 12: $120-125$.

Scavio, M.J.J. and Thompson, R.F. 1979. Extinction and reacquisition performance alternations of the conditioned nictitating membrane response. Bull. Psychonomic Soc. 13: 57-60.

Schmaltz, L.W. and Theios, J. 1972. Acquisition and extinction of a 
classically conditioned response in hippocampectomized rabbits (Oryctolagus cuniculus). J. Comp. Physiol. Psychol. 79: 328-333.

Schneiderman, N. and Gormezano, I. 1964. Conditioning of the nictitating membrane of the rabbit as a function of CS-US interval. $J$. Comp. Physiol. Psychol. 57: 188-195.

Schreurs, B.G., Shi, T., Pineda III, S., and Buck, D.L. 2000. Conditioning the unconditioned response: Modification of the rabbit's (Oryctolagus cuniculus) unconditioning nictitating membrane response. J. Exp. Psychol. Anim. Behav. Proc. 26: 144-156.

Smith, M.C. 1968. CS-US interval and US intensity in classical conditioning of the rabbit's nictitating membrane response. J. Comp. Physiol. Psychol. 66: 679-687.

Smith, M.C. and Gormezano, I. 1965. Effects of alternating classical conditioning and extinction sessions on the conditioned nictitating membrane response of the rabbit. Psychonom. Sci. 3: 91-92.

Solomon, P.R., Vander Schaaf, E.R., Weisz, D.J., and Thompson, R.F. 1986. Hippocampus and trace conditioning of the rabbit's classically conditioned nictitating membrane response. Behav. Neurosci. 100: $729-744$.

Sutherland, N.S. and Mackintosh, N.J. 1971. Mechanisms of animal discrimination learning. Academic Press, New York.

Tyler, D.W., Wortz, E.C., and Bitterman, M.E. 1953. The effect of random and alternating partial reinforcement on resistance to extinction in the rat. Am. J. Psychol. 66: 57-65.

Weible, A.P., McEchron, M.D., and Disterhoft, J.F. 2000. Cortical involvement in acquisition and extinction of trace eye-blink conditioning. Behav. Neurosci. 114: 1058-1067.

Weidemann, G. and Kehoe, E.J. 1997. Transfer and counterconditioning of conditional control in the rabbit nictitating membrane response. Q. J. Exp. Psychol. 50B: 295-316.

2003. Savings in classical conditioning in the rabbit as function of extended extinction. Learn. Behav. 31: 49-68.

. 2004. Recovery of the rabbit's nictitating membrane response without direct reinforcement after extinction. Learn. Behav. 32: $409-426$.

. 2005. Stimulus specificity of concurrent recovery in the rabbit nictitating membrane response. Learn. Behav. 33: 343-362.

Weiss, C., Preston, A.R., Oh, M.M., Schwarz, R.D., Welty, D., and Disterhoft, J.F. 2000. The M1 muscarinic against CI-1017 facilitates trace eyeblink conditioning in aging rabbits and increases the excitability of CA1 pyramidal neurons. J. Neurosci. 20: 783-790.

Received December 14, 2005; accepted in revised form February 6, 2006. 


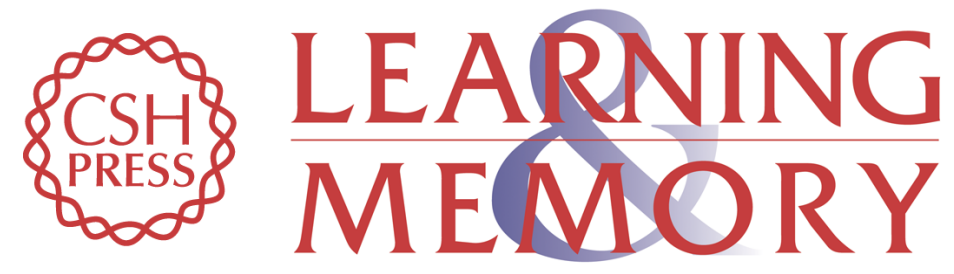

\title{
Repeated acquisitions and extinctions in classical conditioning of the rabbit nictitating membrane response
}

\author{
E. James Kehoe
}

Learn. Mem. 2006, 13:

Access the most recent version at doi:10.1101//m.169306

References This article cites 61 articles, 8 of which can be accessed free at:

http://learnmem.cshlp.org/content/13/3/366.full.html\#ref-list-1

License

Email Alerting Receive free email alerts when new articles cite this article - sign up in the box at the Service top right corner of the article or click here. 